\title{
A Study on the Types of Stories of Edie, a Wit Character in Burma
}

\author{
Lifeng Wang ${ }^{1, *}$
}

${ }^{1}$ Yunnan Normal University, Kunming, Yunnan, China

*Corresponding author. Email: 152499633@qq.com

\begin{abstract}
As an important part of Burmese folk literature, Burmese folklore is an important cultural heritage of Myanmar, which is of multiple research values. This paper analyzes the classification of the stories of Edie, a witty Burmese character, using the AT classification method which is commonly used in the world. It holds that the story of the witty Burmese character Edie is a character that is good at fooling others, selfish, not afraid of power, contemptuous for gods, and goes against the secular order, reflecting his sly character. It is necessary for the academic community to summarize the types suitable for Burmese folk tales.
\end{abstract}

Keywords: Myanmar, a witty character, Edie, story types

\section{INTRODUCTION}

Folk stories are literary works created by the masses collectively and passed down orally. They reflect the social life of human beings as well as the ideals, wishes and values of the masses. As an important part of Burmese folk literature and oriental literature, Burmese folklore is also an important cultural heritage of Myanmar and a treasure of world culture, which is of great research value in many aspects. Wise character story is a genre of folk tales, also known as "witty man's story", which is a series of anecdotes, interesting episode, and jokes about a particular character. Among them, the Burmese folk stories about "Edie", which reflects his wit, no fear of power, disregard of the rules and the image of eloquence, is a vivid embodiment of the Burmese folk stories. Burmese folk literature is not only written in the form of words, but also passed on orally among the Burmese people. It is in urgent need of protection and research.

\section{LITERATURE REVIEW}

The research on witty characters mainly includes Qian Mingzi's "The Uniqueness of Witty Characters' Stories" 1, which distinguishes witty character stories from jokes and summarizes the characteristics of witty character stories, such as

Qian Mingzi. "The Uniqueness of Witty Characters' Stories" [J]. Journal of Beijing Normal University (Social Sciences), No. 5, 1984, pp. 63-69. affinity to the people, anti-religion, concise beauty. Xiao Li's "Study on the Essential Characteristics of Wit Stories of Ethnic Minority Characters" 2 discusses the noumological issues such as the definition, realistic characteristics and boundary of the witty character stories. Gong Weishun's "The Language of the Leading Characters in Yunnan Minority Witty Stories" 3 is the discourse analysis of the speech expression of the stories with clever characters, which also belongs to the study of narrative structure type. Qilianxiu's "Study on the Humor and Interest of the Stories of the Witty Characters of Chinese Nationalities ${ }^{4}$ analyzes the humor characteristics of the stories of witty characters in China, and summarizes their humor and taste into nine different types, such as dislocation method. Huang Yonglin's "On the Search of the Prototype of the AT1635A Story in China" 5 , constructs the story prototype and its spatial distribution range based on the comparison

Xiao Li. Study on the Essential Characteristics of Wit Stories of Ethnic Minority Characters [J]. Studies of Ethnic Literature, 1985, No.1, P 89-95.

$$
\text { Gong Weishun. "The Language of the Leading }
$$
Characters in Yunnan Minority Witty Stories" [J]. Journal of Yunnan Normal University (Humanities and Social Sciences), No.1, 1995.

Qi Lianxiu. "Study on the Humor and Interest of the Stories of the Witty Characters of Chinese Nationalities". Journal of Qiongzhou University (Social Sciences), No.2, 1997, pp. 67-74

Huang Yonglin. On the Search of the Prototype of the AT1635A Story in China [J]. Journal of Central China Normal University (Humanities and Social Sciences), No.3, 2002, pp. 113-119. 
of 51 different AT1635A stories. Thus it can be seen that the research on the literary ontology of witty character stories mainly focuses on smaller genres in the folklore category through the division and comparison of its literary elements such as types, structures and language styles.

There are also some translations and studies of witty Burmese figures in China. For example, in the "Introduction to Oriental Folk Literature Volume III" ${ }^{6}$ compiled by Chen Ganglong and Zhang $\mathrm{Yu}$ 'an, many Burmese wit stories, such as "The Clever Little Novice Monk", "The Arrogant Fatty" and "Chicken Offering", were translated and recorded. In the "Folk Oral Literature of Myanmar in the Cultural and Social Context" ${ }^{7}$ written by Cun Xuetao, a story about a witty Burmese character named "Minister U Paw Oo" is included. In the "Folk Oral Literature of Myanmar in the Cultural and Social Context" ${ }^{8}$ by Cun Xuetao and Chen Xianqing, witty character stories and smart girl stories are put into life stories. The book includes a story about a smart girl, "The Girl Who Saved Her Fiancé", and four stories about witty Burmese characters, such as "King BoDawPaya and Minister U Paw Oo". And Zhang Huimei's "A Study on the Story Types of Witty Character U Paw Oo in Myanmar" 9 , the author uses the method of story typology to classify the collected $\mathrm{Wu}$ Bo-Wu stories and make a brief analysis of them. In her article "A Morphological Study of Myanmar's Amazing Stories", Shen Meilan made a morphological analysis of Myanmar's mythical stories and found that the story forms of Myanmar's mythical stories not only reflect the similarity with Russian and Chinese folk stories, but also display the uniqueness of Myanmar's stories. ${ }^{10}$ In short, there are a lot of translation and collection of witty stories of Burmese characters in China, few indepth studies using scientific methods.

\section{SELECTION OF STORY TEXT}

In this paper, the text of the magic story is mainly selected according to Propp's definition of the magic story, and the text is mainly selected from the translation of the anthologies of domestic

6 Chen Ganglong, Zhang Yu'an. Introduction to Oriental Folk Literature Volume III [M]. Beijing: Kunlun Press, 2006.

Cun Xuetao. Folk Oral Literature of Myanmar in the Cultural and Social Context [M]. Guangdong: World Book Inc, 2010 .

Cun Xuetao, Chen Xianqing. Folk Oral Literature of Myanmar in the Cultural and Social Context [M]. Guangdong: World Book Inc, 2015.

Zhang Huimei. A Study on the Story Types of Witty Character U Paw Oo in Myanmar [D]. Master's Dissertation, Guangxi University for Nationalities, May 2019.

10 Shen Meilan. A Morphological Study of Myanmar's Amazing Stories [D]. Master's Dissertation, Guangxi University for Nationalities, May 2017. published folk stories as the analysis text. The stories of Edie, a witty Burmese character, is included both in "Folk Oral Literature of Myanmar in the Cultural and Social Context" (2015) and "The Collected Records of Burmese Folk Tales". ${ }^{11}$ But the space of these stories is not too much, There are three, respectively "The Godless Edie", "Edie Teasing the King" and "Edie Teasing the Monk". Since the edition of "The Collected Records of Burmese Folk Tales" (2020) is relatively new and provide texts both in Chinese and Burmese, this paper intends to use the story of Edie in this book for analysis

\section{DIVISION PRINCIPLE}

There are four types of catalogs and indexes commonly used by Chinese scholars: Zhong Jingwen's "Types of Chinese Folk Tales", Eberhard's Folktales of China, Ding Naitong's "Index of Types of Chinese Folk Tales", and Jin Ronghua's "Chinese Folk Tales Integrated Type Index (I)". ${ }^{12}$ Compared with various methods which are more suitable for the classification of domestic folk stories, AT classification method is the common method of plot type analysis in the world.

In 1910, Finland's Aarne published the "The Types of the Folktale ", a book that analyzed and compared Nordic folktales, grouped different texts of the same plot into a genre, and then arranged them into categories. In 1928, Thompson in the United States published "The Tale Type Index", which supplemented and revised Arnay's system based on a wider range of folklore sources. Their system of classification is collectively called the Arnai-Thompson system, or AT classification method. It is characterized by the combination of types of subject matter and main theme plot index, which is the most popular classification method in the world today. "Type" is a concept often used in the study of folklore, which refers to a series of folklore works with similar or similar but stereotyped main plots. ${ }^{13}$ The idea of a motif, according to Thompson, is the smallest element of a story that can endure in tradition. ${ }^{14}$ Kang $\mathrm{Li}$ concluded that the "motif" refers to the plot elements or the smallest narrative unit that is difficult to be divided in a folk story. In the text

11 Cun Xuetao, Li Tangying. The Collected Records of Burmese Folk Tales [M]. Kunming: Yunnan People's Publishing House LTD., 2020.

12 Kang Li. Story Types and Plot Types: A Study of Chinese Smart Girl Stories (I), Ethnic Arts, 3rd issue, 2005, P7688.

13 Liu Shouhua, Ed. Exploring the Methodology of Studies on the Type of Chinese Folk Tales [M]. Wuhan: Central China Normal University Press, 2006, P16.

14 [US] Stith Thompson. The Folktale [M]. Translated by Zheng Hai et al. Shanghai: Shanghai Literature and Art Publishing House, 1991, P499. 
analysis of the story, it is found that the formation and development of the plot depend on the connection between the motifs and their ordering. ${ }^{15}$

To sum up, due to the number and type of the three stories selected in the text, the types of Edirelated stories cannot be summed up separately. Therefore, this paper will follow the AT classification method and set the plot types of the stories from the perspective of the motif structure of the three Edi-related stories. In addition, it should be noted that since the analysis text is only three different Edie stories, there is no subtype matter of the same story.

\section{TYPE CLASSIFICATION OF EDIE- RELATED STORIES}

In The Typology of World Folk Tales, Thompson says of wit stories: "It is always difficult to distinguish clumsiness from wit. Once again, the story begins with a series of irrational actions, and we admire its sheer stupidity, but then the stupidity becomes the real wisdom." 16 Therefore, according to the AT classification, the story of the witty character Edie falls into the type of joke in general (AT1200-AT1999). Specifically, Edi-related stories belong to stories about men (boys) and are numbered AT1525-AT1874. In these stories, the man (or boy) is mostly a clever character, using various means to trick someone or get something in order to achieve his aim.

\section{A. The Theft Master (AT1525)}

Edie conned to sell sesame seeds to the king through goofing off and using confusing concept. In "Edie Teasing the King" 17, Edie cheated the king by offering to sell him 100 baskets of sesame seeds. That day, Edie only took out sesame of 1 Myanmar litre to the person coming to fetch the sesame. The person said, "The king asked you to sell 100 baskets to him". Edie replied, "Well, I promised by sell 100 sesame seeds instead of not 100 baskets. Count them and take them away."

According to the Myanmar, Edie not mention corresponding unit of quantity. Since he is selling things to the king, people generally think the unit is the larger one, which is why the king thinks Edie is selling 100 baskets to him. Edie is deliberately obfuscating the number units in order to trick the

15 Kang Li. Story Types and Plot Types: A Study of Chinese Smart Girl Stories (I), Ethnic Arts, 3rd issue, 2005, P7688.

16 [US] Stith Thompson. The Folktale [M]. Translated by Zheng Hai et al. Shanghai: Shanghai Literature and Art Publishing House, 1991, P201.

17 Cun Xuetao, Li Tangying. The Collected Records of Burmese Folk Tales [M]. Kunming: Yunnan People's Publishing House LTD., 2020, p72-74. king, so in this sense he is goofing off and acting in a slick way.

\section{B. Wish Making (AT750A)}

Edie made a wish to the god and asked him to do something for him. As is written the "The Godless Edie" ${ }^{18}$, one day, Edie tied his cow to the god statue and said, "You help me to hold the cow tight so that it won't go home." With nothing to eat, the cow struggled and shake it off. Edie complained "Humph! What god are you? You even cannot pull my cow." So he struck the god with his sword. After he cut off the arm of the statue, he placed it back to the shrine. At the night the god gave a dream to the sorceress and said, "I was cut by Edie and my whole hand was cut off." Unable to stand the wailing of the god, the sorceress connected his hands with iron. When Edie comes back after playing card games, he sees the connected hand and gives it a strike. It is broken again. Then the god cried out, "Look! Help me please! Edie is attacking me!"

This story deeply illustrates the contrast between Edie, a Burmese folk tale figure, and the secular order. Myanmar is a Buddhist country, where people regardless of age, all have the custom of worshiping and respecting Buddha. However, Edie is an exception. He is godless and devious. This kind of "contrast" highlights the heart and character of Edie. There is also a kind of "echo" and "rationality" in the logic of the characters, that is, Edie not only despises the king, but also disregards the gods that people respect.

\section{C. "The Boy on the Wolf's Tail" (AT1875)}

Edie lied to his captors that he had been bitten by a snake and helped him "cure his illness". In the story "Edie Teasing the King" ${ }^{19}$, Once, the king ordered that Edie be arrested. After dark, the man who came to catch Edie was stabbed in the foot by a thorn fruit. Edie lied to him that he was bitten by a snake and promised to cure him. Edie gave his wound a puff of air and fiddle with it, then his captors went back alone.

In the AT classification, numbers 1875-1999 are lying stories, while No.1875 "The Boy on the Wolf's Tail" says, "On both sides of the Atlantic, a man's story is often heard; He held fast to the tail of a wolf and freed himself from a pail, thereby

18 Cun Xuetao, Li Tangying. The Collected Records of Burmese Folk Tales [M]. Kunming: Yunnan People's Publishing House LTD., 2020, p71-72.

19 Cun Xuetao, Li Tangying. The Collected Records of Burmese Folk Tales [M]. Kunming: Yunnan People's Publishing House LTD., 2020, p72-74. 
escaping from danger" ${ }^{20}$ So the scene in which Edie "treats" the wounds of the man who came to capture him, and the wounded man believed he was bitten by a snake, has the same element of exaggeration and grotesque as "The Boy on the Wolf's Tail."

\section{Bragging Game (AT1920)}

Edie described the vulture's nest in the tree as a turtle's nest. There is an episode in "Edie Teasing the King" 21 that when the civil and military ministers came to catch Edie, there was a big bird's nest built by vultures on the kapok tree. Edie was hiding a turtle in his arms. He said there was a turtle nest in the tree. "Huh! Edie, don't be kidding. It's a vulture nest." "No, it's a turtle's nest." He said, "If it is really a turtle's nest, will you set me free? If it is not a turtle's nest, I am willing to die." He had a turtle hidden in his clothes, so he dared to say that. After climbing the tree, there are vulture eggs on the tree, and of course the turtle he brought there. Down to the ground, Edie took out the turtle hidden in his arms said: "not only is it a turtle nest, but also a turtle has been hatched out!" The vulture egg was taken away by him, so the ministers put him free.

Tales of lying or stupidity are widely circulated and may have a variety of origins and histories. The AT classification includes a story of "Bragging Game" that "A liar made the absurd argument that the sea had all been burnt up." Edie deceived the ministers of civil and military affairs and said that upon the tree was a turtle's nest, which was similar to "the sea has been completely burned up", because the sea had all been burnt up, and the turtle cannot be on the tree, which is an exaggeration and violation of the natural law of events.

\section{E. Clever Boy (AT1542)}

Edie devised a scheme so that the man who bet with him would lose. In the story "Edie Teasing the Monks" 22, One day, Edie went to tell the monks that they had been invited to dinner at an temple the next afternoon. The next day, after entering the mountain, Edie said to his fellow mowers, "The dogs in the village are all barking, where are the monks going?" they all said, "Edie, don't talk nonsense!" To which he replied, "Will you bet with me? He signed a note promising that if the dogs in the village did not bark and the monks did not go out, my ox cart and ox will belong to you. If the

20 [US] Stith Thompson. The Folktale [M]. Translated by Zheng Hai et al. Shanghai: Shanghai Literature and Art Publishing House, 1991, P257.

21 Cun Xuetao, Li Tangying. The Collected Records of Burmese Folk Tales [M]. Kunming: Yunnan People's Publishing House LTD., 2020, p72-74.

22 Cun Xuetao, Li Tangying. The Collected Records of Burmese Folk Tales [M]. Kunming: Yunnan People's Publishing House LTD., 2020, p74-75. dogs did bark and the monk did go out, you shall give me all the grass you have cut". They agreed. After the written pledge was signed, Edie fell into a deep sleep. Back in the village, Edie heard the monks complaining, "Ha! Edie told us to go to the temple to have a meal. I don't know where it is. We were walking around the village and the dogs were barking."

In the AT classification, the Clever Boy (Type 1542) tells the story of two siblings living together. They are very poor, and the older brother who makes a living by going out and fooling others. Edie is lazy, and uses his petty trick to fool the monks and his fellow mowers, thus winning the fruits of others' labor. So the plot in this story falls into the same category as "Clever Boy".

\section{CONCLUSION}

The story of Edie, a witty Burmese character, shows a sly character that is good at fooling others, selfish, not afraid of power, contemptuous of gods and goes against the secular order. Edie's characterization is completely different from most of the positive witty characters. He concentrates on deceiving and fooling others, and does not bring much benefit to those around him. In addition, Edie does not possess the dual characteristics of "wisdom" and "foolishness". According to the three selected stories, Edie does not show the characteristics of "foolishness", but displays full "wisdom", which is only used to deceive and fool others to achieve his own goals and interests.

According to the selected three texts, the AT classification method can be used to divide the stories of Edie into four types: Theft Master, Wish Making, The Boy on the Wolf's Tail, Bragging Game and the Clever Boy.

Through the research, it is not difficult to find that AT classification is mainly based on the actual situation of European folk stories, and it is difficult to fit in with the story of Edie, a witty Burmese character based on the historical and cultural traditions of Myanmar. For example, Myanmar's unique Buddhist and god culture and national character cannot be reflected in the AT classification, so the AT classification is not a onesize-fits-all method. Burmese folktales are a treasure of Burmese national culture and show their own special cultural characteristics such as cultural customs, religious beliefs and values. Therefore, it is also necessary to intensify academic research on Burmese folktales and summarize the types suitable for the classification of Burmese folktales. 


\section{References}

[1] [US] Stith Thompson. The Folktale [M]. translated by Zheng Hai et al. Shanghai: Shanghai Literature and Art Publishing House, 1991.

[2] Liu Shouhua, Ed. Exploring the Methodology of Studies on the Type of Chinese Folk Tales [M]. Wuhan: Central China Normal University Press, 2006. (in Chinese)

[3] Liu Shouhua. Comparative Folktale Study [M]. Shanghai: Shanghai Literature and Art Publishing House, 1995. (in Chinese)

[4] Cun Xuetao, Li Tangying. The Collected Records of Burmese Folk Tales [M]. Kunming: Yunnan People's Publishing House LTD., 2020. (in Chinese)

[5] Xiao Li. Study on the Essential Characteristics of Wit Stories of Ethnic Minority Characters [J]. Studies of Ethnic Literature, 1985, No.1. (in Chinese)

[6] Huang Longguang. The Value and Research of the Series Stories of the Wit Character Pop Piet of Yi Nationality [J]. Journal of Chongqing Three Gorges University, No.3, 2020. (in Chinese)

[7] Kang Li. Story Types and Plot Types: A Study of Chinese Smart Girl Stories (I), Ethnic Arts, 3rd issue, 2005. (in Chinese)

[8] Zhang Huimei. A Study on the Story Types of Witty Character U Paw Oo in Myanmar [D]. Master's Dissertation, Guangxi University for Nationalities, May 2019. (in Chinese) 